\title{
COVID-19 NO ESTADO ESPANHOL: DA CRISE SANITÁRIA À CRISE DO PROCESSO
}

\author{
ANTONIO JOSÉ VÉLEZ TORO ${ }^{1}$
}

RESUMO: A crise sanitária causada pela COVID-19 em Espanha, com a limitação das acções presenciais, e de uma forma singular as audiências orais, está a causar uma redução das garantias processuais no que diz respeito aos princípios de imediatismo e oralidade. Isto afecta directamente o direito de defesa e o direito fundamental à protecção judicial efectiva, sem esquecer que com as reduções processuais (lei instrumental) vem a liquidação dos direitos (substantivos).

Palavras-Chave: Processo civil; Crise do processo; Oralidade; Imediação; Proteção judicial efetiva.

RESUMEN: La crisis sanitaria originada por el COVID-19 en el Estado español, con la limitación de las actuaciones presenciales, y de modo singular las vistas orales, está originando una rebaja de garantías procesales en cuanto a los principios de inmediación y de oralidad. Ello afecta directamente al derecho de defensa y al derecho fundamental a la tutela judicial efectiva, sin olvidar que con las rebajas procesales (derecho instrumental) llega la liquidación de los derechos (sustantivos).

Palabras Clave: Proceso civil; Crisis del proceso; Oralidad; Inmediación; Tutela judicial efectiva.

\footnotetext{
${ }^{1}$ Advogado e Doutor em Direito. Professor substituto em exercício na Universidade de Granada. Grupo de investigação ESTUDIOS PROCESALES SEJ-422. Contato: velez.abogados@gmail.com.
} 


\section{INTRODUÇÃO}

Embora a crise sanitária tenha provocado medidas em todas as jurisdições ${ }^{2,}$ por razões de espaço limitaremos este estudo aos seus efeitos sobre o processo civil.

Em primeiro lugar, falar sobre o impacto da COVID-19 na administração da justiça espanhola é falar de novas oportunidades para a redução de garantias, em linha com a tendência neoliberal. Assim, na sequência dos processos de privatização nos anos 80 e de desregulamentação nos anos 90, a partir de 2000, coincidindo com a nova LEC, foram realizadas sucessivas reformas no processo civil, as mais importantes em 2009, 2011, 2012 e 2015, que têm em comum o facto de constituírem um instrumento dissuasivo para o recurso ao processo civil, ou seja, a área onde pode ser exercido um conjunto de garantias para a protecção de direitos e interesses legítimos. Vejamo-los:

A reforma de 2009 foi articulada através da Lei 13/2009, de 3 de Novembro, sobre a Reforma da Legislação Processual para a Implementação do Novo Poder Judicial e da Lei Orgânica 1/2009, de 3 de Novembro, que complementa a Lei sobre a Reforma da Legislação Processual para a Implementação do Novo Poder Judicial, que modificou a Lei Orgânica 6/1985, de 1 de Julho, sobre o Poder Judicial. O objectivo desta reforma era conceder poderes jurisdicionais aos Secretários Judiciais, agora chamados Advogados da Administração da Justiça, incluindo a resolução de recursos das suas próprias resoluções (Recurso de Revisão), que foi parcialmente anulado no que diz respeito ao necessário controlo judicial das resoluções dos referidos Advogados da Administração da Justiça, pelo STC 58/2016, de 17 de Março. No entanto, a verdade é que esta reforma sobreviveu com a intenção de modernizar os tribunais sem aumentar os seus recursos financeiros.

A Lei 37/2011, de 10 de Outubro, sobre medidas para acelerar os processos, no domínio do processo civil, tornou os processos de despejo mais rigorosos e restringiu o acesso ao processo de recurso, elevando o montante mínimo de recurso para 3.000 euros no processo civil (ex-arte. 455 LEC). Isto foi possível graças ao STC 37/1995, de 7 de Fevereiro, que deixou ao critério do legislador o estabelecimento de dupla incriminação em jurisdições não penais, de modo a que o direito de recurso só possa ser exercido se o legislador assim o estabelecer, e possa ser restringido ou completamente banido de processos civis, embora também possa ser banido de todas as outras jurisdições não penais.

Em 2012, o Real Decreto-Lei 5/2012 de 5 de Março sobre mediação em matéria civil e comercial e a Lei 5/2012 de 6 de Julho sobre mediação em matéria civil e comercial promoveram a mediação intra-judicial. Enquanto que a Lei 10/2012 de 20 de Novembro estabeleceu taxas judiciais para o acesso à justiça até à sua anulação parcial pelo STC 140/2016 de 21 de Julho.

\footnotetext{
2 Sobre as reformas em curso no processo penal, ver Torres Rosell, N., "La aceleración de la actividad judicial depende de la restricción de derechos procesales: modificación y supresión de recursos en el proceso penal (propuestas 4.6 y 4.13 del CGPJ)", Diario La Ley, No. 9664, Sección Plan de Choque de la Justicia / Tribuna, 1 de Julio de 2020, s/p.
} 
A Lei 42/2015, de 5 de Outubro, que reforma a Lei 1/2000, de 7 de Janeiro, de Processo Civil, cedeu as prerrogativas do Ministério Público à figura do Procurador - que é um representante qualificado e cuja acção é obrigatória em processo civil, excepto para os processos que envolvam montantes inferiores a 2000 euros - para realizar os procedimentos de notificação do arguido (ex-arte. 152 LEC), bem como a restrição do processo oral quando as partes têm de solicitar expressamente uma audiência oral (ex-arte. 438.4 LEC).

Assim, o processo tem vindo a deteriorar-se, se não a fugir dele, o que tem sido articulado através de sucessivas reformas legislativas que dificultam o seu acesso directo (limitando recursos e garantias processuais), ou indirectamente, tornandoo mais caro (o que é também uma forma de o evitar).

Em segundo lugar, por ocasião da crise sanitária causada pela COVID-19, uma crise silenciosa materializou-se na separação de poderes, uma vez que o Conselho Geral da Magistratura (a seguir, CGPJ), que é o órgão dirigente dos juízes, tomou a iniciativa legislativa. Desta forma, a CGPJ estabeleceu o roteiro para o Ministério, o Governo e o próprio Parlamento. Do ponto de vista constitucional - embora ninguém o note - constitui uma usurpação da iniciativa legislativa e, ao assumi-la, o poder judicial invade parcelas de terra pertencentes ao poder executivo. Assim, à crítica da inexistência na prática da separação de poderes entre o executivo e o legislativo junta-se agora a figura do juiz-legislador.

\section{ANÁLISE DA REFORMA REALIZADA}

Tendo em conta a suspensão da actividade económica devido à pandemia e a previsível avalanche de acções judiciais em resultado da declaração do estado de alarme ${ }^{3}$, as várias propostas que foram feitas pelo $\mathrm{GPCJ}^{4}$, na nossa opinião, estão a levar à "não realização de audiências orais", o que constitui uma violação do princípio do imediatismo, ${ }^{5} \mathrm{como}$ percepção e contacto directo do juiz com as partes, os seus advogados e as provas ${ }^{6}$. Isto, por sua vez, constitui uma grave violação dos princípios da igualdade processual, contradição e prova, e constitui um ataque

\footnotetext{
${ }^{3}$ Decreto Real 463/2020, de 14 de Março, que declara o estado de alerta para a gestão da situação de crise sanitária causada pela COVID-19 (Ref. BOE-A-2020-3692)

4 http://www.poderjudicial.es/cgpj/es/Poder-Judicial/En-Portada/La-Comision-Permanente-delCGPJ-toma-conocimiento-del-documento-de-trabajo-definitivo-de-medidas-organizativas-yprocesales-del-plan-de-choque-para-la-Administracion-de-Justicia-tras-el-estado-de-alarma.

${ }^{5}$ Ver, Herrera Abián, R., La immediación como garantía procesal (en el proceso civil y penal), Granada, Comares, 2006.

${ }^{6}$ Ver Wach, A., Conferencias sobre la Ordenanza Procesal Alemana, traduzido por Krotoschin, E., Buenos Aires, Ediciones Jurídicas Europa-América, p. 2; Chiovenda, G. , Instituciones de Derecho Procesal Civil, Vol. III, trad. Gómez Orbaneja, E., Madrid, Ed. Rev. Derecho Privado, 1954, p. 177, s.; Fairén Guillén, V. Teoría General del Derecho Procesal, México DF, UNAM, 1992, p. 401, s.; Montero Aroca, J., "La nueva Ley de Enjuiciamiento Civil Española y la Oralidad", Derecho PUCP, No. 53, 2000, p. 622, La immediación como garantía procesal (en el proceso civil y penal), Granada, Comares, 2006, p. 8, ff.
} 
directo ao direito de defesa e ao direito a uma protecção judicial eficaz, uma vez que teremos ocasião de analisar.

Assim, na sequência das indicações da CGPJ, o Governo espanhol procedeu a ditar o Real Decreto-Lei 16/2020, de 28 de Abril, de medidas processuais e organizacionais para fazer face à COVID-19 na área da Administração da Justiça (a partir de agora, RDL 16/20), validado pelo Acordo de 13 de Maio de 2020, do Congresso dos Deputados.

Especificamente, o RDL 16/20 contém três blocos de medidas urgentes. Em primeiro lugar, as disposições destinadas a retomar a actividade ordinária dos tribunais, para o que prorroga os prazos processuais para a interposição de recursos, uma vez cessado o estado de alarme; além disso, reduz a cessação da actividade dos tribunais em Agosto, de modo que a partir do dia 11 deste mês a actividade judicial é retomada; da mesma forma, estabelece horários de manhã e de tarde para os funcionários da justiça.

É de notar a criação de um procedimento de transição em matéria familiar, conhecido $^{7}$ como "urgente e sumário", que visa restabelecer um equilíbrio no sistema de visitas ou custódia partilhada devido a restrições de mobilidade durante o estado de emergência, rever as pensões estabelecidas por ocasião de processos de divórcio entre cônjuges e para os filhos, e sobre o estabelecimento ou revisão dos direitos de alimentos. Para o efeito, é criado nos seus artigos um procedimento especial e efémero de resumo familiar. Artigos 3 a 5, cujas principais características são (1) a eliminação das respostas escritas, (2) a audição de crianças menores antes da audiência, (3) a realização imediata da audiência no prazo de 10 dias, (4) a limitação das provas a serem apresentadas na audiência, permitindo excepcionalmente a obtenção de provas após a audiência, e (5) a entrega da sentença oralmente ou por escrito no prazo de três dias úteis.

Embora este processo esteja programado para durar durante o estado de alarme e para os três meses seguintes (ex-arte 3 RDL 16/20), não podemos ignorar que poderia ser perpetuado, com a consequente perda de garantias em relação ao processo padrão (com respostas escritas e testes após a audiência oral) como é actualmente o caso.

O bloco termina com a falência e as medidas empresariais nos artigos 8 a 18 da RDL 16/20.

Contudo, as disposições da Lei estão contidas no capítulo III (arts. 19-28 da RDL 16/20), e em particular as relativas à realização de actos processuais por meios telemáticos (art. 19), bem como a restrição às salas de audiência (art. 20), aos exames médico-farmacêuticos (art. 21) e ao chamado serviço público (art. 23).

Por outro lado, a Ordem JUS/394/2020 de 8 de Maio, que aprova o Esquema de Segurança Laboral e o Plano de Diminuição da Escalada para a Administração da Justiça perante a COVID-19, estabelece fortes limitações ao acesso público aos gabinetes judiciais, mantendo-se em silêncio sobre o acesso de advogados e

\footnotetext{
${ }^{7}$ Ver Torres Rosell, N., «¿Era necesario y útil el nuevo procedimiento en derecho de familia?», Diario La Ley, No. 9656, Sección Plan de Choque de la Justicia / Tribuna, 18 de Junho de 2020, s/p.
} 
advogados, o que na prática limita o acesso aos processos judiciais em todas as ordens. Neste sentido, deve ser esclarecido que tanto os advogados como os procuradores públicos não podem ser incluídos na categoria de "público" ou "utilizadores" da Administração da Justiça. Pelo contrário, a própria LOPJ define os advogados, procuradores e procuradores como profissionais "que cooperam com a Administração da Justiça".

$\mathrm{Na}$ prática, estão a ser criadas situações verdadeiramente absurdas e contraproducentes do ponto de vista do risco sanitário que estamos a tentar proteger, dado que o advogado convocado para o julgamento não pode tirar partido da sua presença no tribunal para consultar um processo, do mesmo tribunal ou de outro, uma vez que lhe falta a marcação prévia necessária; $\mathrm{O}$ advogado tem de solicitar uma marcação prévia para cada órgão judicial, mesmo para aqueles que se encontram no mesmo local, o que faz com que cada tribunal conceda a marcação prévia em dias e horas diferentes, tendo de multiplicar o número de vezes que vai ao mesmo edifício judicial para cada uma das marcações em dias e horas diferentes, em vez de concentrar o trabalho e fazer uma única visita ao edifício judicial para consultar os ficheiros nos diferentes tribunais. Sem dúvida, neste momento, o exercício da defesa confiada à profissão de advogado em Espanha está a ser dificultado. Em muitos casos, são mesmo os membros das forças de segurança do Estado que desempenham tarefas de custódia nos pontos de acesso ao edifício do tribunal, que avaliam e determinam o motivo alegado pelo advogado para lhe permitir o acesso ao edifício do tribunal.

No caso acima mencionado, devemos remeter para as disposições do artigo 234 da LOPJ e dos artigos 140 e 141 da LEC no que respeita ao acesso a processos judiciais por qualquer parte interessada; deve também ser feita referência ao Regulamento 1/2005 da CGPJ sobre aspectos acessórios dos processos judiciais, que no artigo 2.1 estabelece:

Os interessados terão acesso aos livros, arquivos e registos judiciais que não sejam de natureza reservada, através das formas de exposição, testemunho ou certificação estabelecidas pela lei, em conformidade com as disposições do artigo 235 da LOPJ.

Do mesmo modo, o Artigo 546 da LOPJ estabelece a obrigação das autoridades públicas de garantir a defesa e assistência do Advogado nos termos estabelecidos na Lei, de modo que a possível limitação do acesso à sede judicial violaria também este preceito.

Mais grave é o facto de a instância judicial determinar que os actos processuais, tais como comparências, interrogatórios, obtenção de provas ou a realização de audiências orais são realizados por meios telemáticos, sem qualquer contacto directo com as partes, os seus defensores ou as provas. Isto está previsto no artigo 19.1 RDL 16/20, que diz

Durante a vigência do estado de alarme e até três meses após a sua conclusão, o Tribunal ou Tribunal é constituído na sua sede, os 
actos de julgamento, comparências, declarações e audiências e, em geral, todos os actos processuais, serão realizados de preferência por meio de presença telemática, desde que os Tribunais, Tribunais e Procuradores tenham os meios técnicos necessários à sua disposição.

Contudo, esta regra geral não se aplica aos julgamentos penais por delitos graves (Artigo 19(2) RDL 16/20).

\section{CONSIDERAÇÕES CRÍTICAS}

A análise do processo judicial conduz necessariamente à oralidade, que pode ser definida como a forma prevalecente do processo, por oposição à escrita. Assim, o princípio da oralidade é oposto ao princípio da escrita ${ }^{8}$.

Na doutrina, Wach concebe a "oralidade" como "a percepção imediata da questão processual pelo juiz que está a ouvir o caso". Consiste no facto de só o que é directamente percebido pelo juiz é a base da sentença" ${ }^{9}$. Chiovenda entende a oralidade como a "predominância da palavra falada como meio de expressão, temperada pela utilização de escritos e documentação preparatória" ${ }^{10}$. Salienta que "a discussão oral deve ser a conclusão imediata de uma argumentação oral", acrescentando que "o princípio da oralidade não exige precisamente que a escrita seja dispensada no processo". $\mathrm{Na}^{11}$ medida em que o pedido e a indicação da prova são considerados documentos preparatórios, tal como a declaração de defesa do arguido, para o processo oral ${ }^{12}$.

Entre os autores espanhóis, Beceña diz que "no procedimento oral o centro de gravidade do processo cai sobre a audiência", implica "a necessidade de o juiz confrontar as partes directamente e desde o início do processo, chegando ao fundo da questão por conhecimento directo" ${ }^{13}$. Majada, por seu lado, concebe o processo oral "como o princípio do direito processual civil que advoga uma actividade processual rápida, com os primeiros escritos de reclamação e resposta, de acordo com os princípios da prontidão e concentração na obtenção de provas, sendo a

\footnotetext{
8 Fairén Guillén, V. Teoría General del Derecho Procesal, México DF, UNAM, 1992, p. 407, define o princípio da escrita como aquele princípio segundo o qual as acções básicas do procedimento são formuladas por escrito, considerando como consequências lógicas do princípio da escrita os princípios da preclusão e o princípio da "eventualidade": isto é, que quando uma "oportunidade legal" se abre para as partes, esta deve aproveitar-se dela (p. 408, s).

9 Wach, A., Conferencias sobre la Ordenanza Procesal Alemana, tradução de Krotoschin, E., Buenos Aires, Ediciones Jurídicas Europa-América, 1958, p. 1.

${ }^{10}$ Chiovenda, G. Instituciones de Derecho Procesal Civil, Vol. III, trad. Gómez Orbaneja, E., Madrid, Ed. Rev. Derecho Privado, 1954, p. 173, s.

${ }^{11}$ Chiovenda, G. Instituciones de Derecho Procesal Civil, Vol. III, trad. Gómez Orbaneja, E., Madrid, Ed. Rev. Derecho Privado, 1954, p. 174.

${ }^{12}$ Chiovenda, G. Instituciones de Derecho Procesal Civil, Vol. III, trad. Gómez Orbaneja, E., Madrid, Ed. Rev. Derecho Privado, 1954, p. 175.

${ }^{13}$ Notas de Derecho Procesal Civil, 1932, Madrid, (n.d.) Litografía E. Nieto, p. 335.
} 
sentença proferida após um relatório oral conciso"14. Finalmente, para Montero Aroca "o princípio da oralidade significa, em primeiro lugar, que nos actos processuais, o que é falado predomina sobre o que é escrito, como meio de expressão e comunicação entre os diferentes sujeitos que intervêm no processo" 15 ; e acrescenta que caracteriza o procedimento oral para "terminar com uma audiência em que o juiz se coloca em relação directa com as provas pessoais (testemunhas e peritos) e com as partes", resultando no seu conceito de um julgamento oral completo a partir do julgamento oral originado no LEC e do julgamento ordinário ${ }^{16}$.

Quanto aos elementos do processo em que a oralidade pode operar, Cappelletti analisa o significado do princípio da oralidade em relação à proposta da exigência - que ele considera dever ser escrita -, os argumentos jurídicos - dos quais ele mostra preferência pela forma escrita - e as provas, para as quais ele reivindica a oralidade necessária ${ }^{17}$.

Obviamente, o princípio da oralidade implica necessariamente imediatismo, concentração e publicidade.

O princípio do imediato refere-se à percepção directa e ao contacto do juiz com as partes, os seus advogados e as provas ${ }^{18}$. O princípio da concentração implica a necessária unidade do acto do julgamento, que deve ser materializada no menor número possível de sessões ou audições ${ }^{19}$. Finalmente, o princípio da publicidade exige que o processo seja conduzido de forma pública, tanto para as partes como para o público ${ }^{20} \mathrm{em}$ geral. Além disso, os princípios acima referidos implicam o

${ }^{14}$ Técnica de denúncia perante tribunais e tribunais. Oratório Forense, 5ae ed., Barcelona, Bosch, 1991, p. 58.

${ }^{15}$ Montero Aroca. "La nueva Ley de Enjuiciamiento Civil Española y la Oralidad", Derecho PUCP, No. 53, 2000, p. 621, s.

${ }^{16}$ Montero Aroca. "La nueva Ley de Enjuiciamiento Civil Española y la Oralidad", Derecho PUCP, No. 53, 2000, p. 622.

${ }^{17}$ Cappelletti, M., La oralidad y las pruebas en el proceso civil, trad. Sentis Melendo, S., Buenos Aires, EJEA, 1972, p. 87, s.

${ }^{18}$ Ver Wach, A., Conferences on German Procedural Law, op. cit., p. 2; Chiovenda, G. , Institutions of Civil Procedure Law, Vol. III, op. cit., p. 177, s.; Fairén Guillén, V. Teoria Geral do Direito Processual, op. cit., p. 401, s.; Montero Aroca, J., "La nueva Ley de Enjuiciamiento Civil Española y la Oralidad", art. cit., art. cit., p. 401, s.; Montero Aroca, J., "La nueva Ley de Enjuiciamiento Civil Española y la Oralidad", art. cit, La immediación como garantía procesal (en el proceso civil y penal), Granada, Comares, 2006, p. 8, ff., considera o imediatismo como uma consequência inevitável da oralidade, e os princípios de oralidade, imediatismo, concentração e publicidade são indispensáveis.

${ }^{19}$ Cf. Wach, A., Conferências sobre o Direito Processual Alemão, op. cit., p. 45, "A concentração do debate oral é indispensável". Na mesma linha, ver Chiovenda, G., Instituciones de Derecho Procesal Civil, Vol. III, op. cit., p. 178; Montero Aroca, J., "La nueva Ley de Enjuiciamiento Civil Española y la Oralidad", art. cit, "Oralidad y escritura como factores de eficiencia en el proceso civil (Versión abreviada)", em Carpi, F., Ortells, M. (Editores), Oralidad y escritura en un proceso civil eficiente, Vol.I: Ponencias generales e informes nacionales, Valencia, Universidad de Valencia, 2008, p. 366, s.

${ }^{20}$ Sobre o princípio da publicidade, ver, Fairén Guillén, V. General Theory of Procedural Law, op. 
consequente aumento dos poderes do juiz, que não pode manter uma posição de pura passividade ${ }^{21}$.

Como corolário, e se tivermos em conta a reforma feita pela Lei 42/2015, o actual julgamento oral está próximo do ideal pregado por Wach: "O ideal do julgamento oral é a concentração numa única audiência dos argumentos, declarações, ofertas de provas, excepções de provas e, se possível, a recepção de provas de todas as partes" 22 .

\subsection{O princípio da oralidade na constituição espanhola}

O princípio da oralidade está consagrado no artigo 120(2) do Tratado CE, ${ }^{23}$ que o prevê: "Os processos devem ser orais, especialmente em matéria penal".

O princípio constitucional da oralidade é ainda reforçado na própria Carta Magna com a exigência de que "os processos judiciais serão públicos, com as excepções previstas nas leis processuais" (Artigo 120.1 CE) ${ }^{24}$. Da mesma forma, o Artigo 24 do CE declara que "toda a gente tem direito ... a um julgamento público sem demora injustificada" 25 .

Deve salientar-se que os princípios do processo oral e da publicidade do processo judicial são princípios constitucionais, e que estes princípios implicam necessariamente a imediatez e concentração do processo judicial.

cit., p. 410, ss.; Montero Aroca, J., "La nueva Ley de Enjuiciamiento Civil Española y la Oralidad", art. cit, "El principio de Oralidad en el Proceso Civil Español", em Carpi, F., Ortells, M. (Editores), Oralidad y escritura en un proceso civil eficiente, Vol.

${ }^{21}$ Chiovenda, G. , Instituciones de Derecho Procesal Civil, Vol. III, op. cit., p. 188, " Urge, por consiguiente, asegurar al juez una posición que le haga partícipe activo en la regulación procesal, y proveerle de la autoridad necesaria para ejercer su función". Ao que acrescenta que " el ejercicio de estas facultades sólo es posible en el proceso oral. Puesto que sólo él permite el contacto inmediato y continuo del juez con las partes y sus representantes". Por outro lado, Montero Aroca, J., "La nueva Ley de Enjuiciamiento Civil Española y la Oralidad", art. cit., p. 635, impede e especifica que "Una cosa es aumentar los poderes respecto del proceso mismo (en su regularidad formal, en el control de los presupuestos procesales, en el impulso, por ejemplo) y otra aumentarlas con relación al contenido del proceso y de modo que pueda llegarse a influir en el contenido de la sentencia".

${ }^{22}$ Wach, A. , Conferências sobre Direito Processual Alemão, op. cit., p.

${ }^{23}$ Ver Gutiérrez-Alviz y Armario, F.; Moreno Catena, V., "Artículo 120. Actuaciones judiciales", in Alzaga Villaamil, O., Comentarios a la Constitución Española de 1978, Tomo IX, Madrid, Cortes Generales-Editoriales de Derecho Reunidas, 1996, p. 399, ss.; Garberí Llobregat, J., Constitución y Derecho Procesal. Los fundamentos constitucionales del Derecho Procesal, $1^{\underline{a}}$ ed., Madrid, CivitasThomson Reuters, 2009, p. 324, s.

${ }^{24}$ Ver Gutíerrez-Alviz y Armario, F.; Moreno Catena, V., "Artículo 120. Actuaciones judiciales", in Alzaga Villaamil, O. , Comentarios a la Constitución Española de 1978, op. cit. Los fundamentos constitucionales del Derecho Procesal, op. cit., p. 271, ss., e 326, ss.; Picó i Junoy, J. , Las garantías constitucionales del proceso, $2^{\underline{a}}$ ed.

${ }^{25}$ Ver Díez-Picazo Giménez, I., "Artículo 24", in Alzaga Villaamil, O. , Comentarios a la Constitución Española de 1978, Tomo III, Madrid, Cortes Generales-Editoriales de Derecho Reunidas, 1996, p. 81 , ss. 
O princípio da urgência refere-se ao acesso directo do juiz às provas e argumentos das partes, de modo a que as provas sejam recolhidas na sua presença. Isto implica uma concentração do processo, a fim de evitar "atrasos indevidos" (ex artigo 24(2) CE).

Que o princípio da oralidade requer imediatismo judicial foi reconhecido pelo STC 64/1993, de 1 de Março, Primeira Câmara:

(...) no processo oral, apenas a instância judicial que testemunhou a apresentação oral do material factual e jurídico e, se for caso disso, a obtenção de provas, tem o direito de julgar ou, por outras palavras, a natureza oral do processo exige que este seja apresentado a um tribunal" (FJ $3^{\circ}{ }^{26}$.

O Artigo 120(2) CE é coerente com o Artigo 6 da Convenção Europeia dos Direitos do Homem (CEDH), que declara: "Toda a pessoa tem direito a uma audiência justa e pública dentro de um prazo razoável", o que implica, inexplicavelmente, um processo oral ${ }^{27}$.

A LOPJ, no capítulo dedicado à oralidade, publicidade e língua oficial e após reproduzir no parágrafo 1 do artigo $229^{\circ}$ o texto do artigo 120.2 CE - com o aditamento "sem prejuízo da sua documentação" -, diz no parágrafo 2 que: "As declarações, interrogatórios, testemunhos, confrontos, explorações, relatórios, ratificação dos peritos e audiências, serão efectuadas perante o juiz ou tribunal com a presença ou intervenção, se necessário, das partes e em audiência pública, com excepção do que for estabelecido por lei".

Por seu lado, a LEC inclui o princípio da oralidade no artigo 185 e concordante em geral, ${ }^{28} \mathrm{sem}$ prejuízo das regras específicas do procedimento ordinário (artigos $414^{\circ}$ a $430^{\circ}$ para a audiência prévia e, se for caso disso, artigos $431^{\circ}$ a $433^{\circ}$ LEC $^{\circ}$ para o julgamento) e para a oral (artigos $442^{\circ}$ a $446^{\circ}$ LEC). A imunidade exige a "presença judicial em declarações, provas e audiências" (art. 137 LEC), ou seja, o juiz e os magistrados que compõem o tribunal que está a apreciar o caso.

O princípio do imediatismo está estabelecido no artigo 137 que exige a presença judicial (de juízes e magistrados do tribunal ou do tribunal a quem o caso é submetido) quando um acto prescrito pela LEC tem de ser realizado "contraditória e publicamente" ou as partes têm de ser ouvidas antes de ser tomada uma decisão.

${ }^{26}$ Neste sentido, Gutiérrez Barrengoa, "La oralidad y sus implicaciones en el proceso civil", em Carpi, F., Ortells, M. (Editores), Oralidad y escritura en un proceso civil eficiente, Vol.

${ }^{27}$ Storme, M., "Mais voz, menos letra": En defensa de la oralidad en los procesos judiciales (versión resumida)", in Carpi, F., Ortells, M. (Editores), Oralidad y escritura en un proceso civil eficiente, Vol. I: Ponencias generales e informes nacionales, Valencia, Universidad de Valencia, 2008, p. 49, ss., destaca a oralidade no art. 6 da $\mathrm{CEDH}$, bem como a prevalência dos procedimentos orais para aumentar a eficiência processual.

${ }^{28}$ Ver, Picó e Junoy, J., "El principio de Oralidad en el Proceso Civil Español", in Carpi, F., Ortells, M. (Editores), Oralidad y escritura en un proceso civil eficiente, Vol. 
Quanto ao princípio da publicidade, este está contido no artigo 138 LEC, intitulado "Publicidade do processo oral", que prevê que: "1. Os parágrafos 2 e 3 estabelecem os casos em que os procedimentos podem ser realizados à porta fechada.

Finalmente, o princípio da concentração é estabelecido no artigo 193 da LEC, através de uma série de regras para a restrição de interrupções de audições.

\subsection{Oralidade e processo civil}

Tendo estabelecido que tanto os julgamentos verbais como os ordinários são predominantemente orais, ${ }^{29}$ é agora apropriado determinar os índices de oralidade como resultado da crise causada pela COVID-19.

Apesar do facto de a Lei 42/2015, de 5 de Outubro, equiparar a regulamentação do processo oral à do processo ordinário, pondo fim ao debate sobre a insegurança gerada pelas respostas orais, constatamos que o novo "procedimento especial e sumário em matéria familiar" e alimentar (ex art. 3 a 5 RDL 16/20) constitui um retrocesso ao regressar às surpresas inerentes às respostas orais. Isto é ainda agravado pela falta de um procedimento específico para esclarecimentos, rectificações e reclamações complementares no julgamento oral, semelhante ao que existe no julgamento normal (ex-arte 426.1, 2 e 3 LEC), o que deixa o novo "procedimento especial e sumário em assuntos familiares" ainda mais desprovido de flexibilidade. Além disso, não existe um procedimento específico para fornecer novos factos ou novas informações com a sua correspondente contribuição documental, pelo que devem ser utilizadas as regras gerais de rectificação (arts. 243 LOPJ e 231 LEC).

No que respeita à prática da prova no novo procedimento especial e sumário, a oralidade é limitada pelas dificuldades em interrogar as partes e testemunhas sobre pessoas colectivas e entidades sem personalidade (arts. 309 e 381 LEC), bem como pela impossibilidade de interrogar pessoas colectivas e entidades públicas (ex-art. 440.1 e 315 LEC).

A questão das testemunhas também é complicada pelo facto de serem propostas na própria audiência, e a questão deve ser formulada oralmente mas acompanhada de provas (excluindo o depoimento). A prova pericial pode ser reduzida a mera prova documental, em detrimento da prova oral ${ }^{30}$.

Caso contrário, o reconhecimento judicial referido aos locais implica a suspensão da audiência, tendo um mau ajuste, excepto para as disposições do artigo 441.2 LEC para os julgamentos verbais sumários de suspensão de novos trabalhos. Consequentemente, deve ser considerada como uma questão de lege

\footnotetext{
${ }^{29}$ Montero Aroca, J., "La nueva Ley de Enjuiciamiento Civil Española y la Oralidad", Derecho PUCP, No. 53, 2000, p. 622.

30 Sobre a necessidade de ratificação de relatórios de peritos, ver, Richard González, M., "Limitaciones a la oralidad en la práctica de la prueba pericial en el proceso civil español", in Carpi, F., Ortells, M. (Editores), Oralidad y escritura en un proceso civil eficiente, Vol.
} 
ferenda a necessidade de estender a sua utilização anterior à audiência nos outros julgamentos verbais.

No final, a reforma implementada pela RDL 16/20 constitui uma violação na prática - por muito transitória que seja - dos princípios do imediatismo, publicidade e oralidade proclamados na Exposição de Motivos da LEC (XII, parágrafo 8: "A Lei concebe processos declarativos de tal forma que o imediatismo, a publicidade e a oralidade devem ser eficazes") ${ }^{31}$. Não devemos esquecer que o processo oral aproxima o arguido, permitindo - em matéria de alegações e provas - um "debate bilateral" entre o juiz e as partes, uma vez que na prática da prova tanto os próprios arguidos como, sobretudo, o próprio chefe da instância judicial podem solicitar os esclarecimentos que considerem necessários ${ }^{32}$.

Por conseguinte, consideramos que a prevalência adequada do princípio do processo oral em processo civil deve levar à revogação imediata dos artigos 19, 20 e 23 da RDL 16/20. Por outras palavras, há uma necessidade urgente de restabelecer no processo civil o carácter obrigatório da audiência oral, para que o juiz possa ouvir em primeira mão as discrepâncias no litígio, e pedir esclarecimentos e detalhes das reivindicações das partes (ex art. 443‥3 LEC) e no material probatório, bem como para indicar a necessidade de completar as provas propostas (ex-arte 443.3.II LEC) e para ouvir, pelo menos, as conclusões das partes relativamente às provas recolhidas - mesmo quando são documentais -, em conformidade com as disposições do art. 447.1 LEC.

\section{CONCLUSÕES}

1.- As limitações ao direito à protecção judicial efectiva impostas pela RDL 16/20 levantam dúvidas quanto à sua constitucionalidade. Neste ponto, deve recordar-se que a Constituição espanhola concebe o processo judicial como o meio mais adequado para resolver todos os tipos de conflitos intersubjectivos. Assim, através do processo, os tribunais desempenham exclusivamente a função jurisdicional (Artigo 117.3 CE) para a resolução de conflitos de interesse e a protecção do Estado de direito (Artigo 1.1 CE), a realização da paz social para os cidadãos (Artigo 10.1 $\mathrm{CE})$, e a sua protecção contra os funcionários públicos ${ }^{33}$.

Assim, entre os meios de resolução de conflitos, a Constituição inclui apenas o processo, sem fazer qualquer menção aos outros instrumentos de resolução de conflitos, quer sejam heterocompositivos - como a arbitragem - ou autocompositivos - como a mediação ou a conciliação ${ }^{34}$.

\footnotetext{
${ }^{31}$ Picó e Junoy, J., "El principio de Oralidad en el Proceso Civil Español", in Carpi, F., Ortells, M. (Editores), Oralidad y escritura en un proceso civil eficiente, Vol.

${ }^{32}$ Martín Diz, F., "Oralidad y eficiencia del proceso civil: Ayer, hoy y mañana", em Carpi, F., Ortells, M. (Editores), Oralidad y escritura en un proceso civil eficiente, Vol.

33 Ver, entre outros, STC 175/2001 de 26 de Julho (FJ 4 e 6).

34 Sobre autocomposição (conciliação e mediação) e processo, ver Alcalá-Zamora y Castillo, N., Proceso, autocomposição e autodefesa. Contribuição para o estudo dos fins do processo, reimpressão da 3ª ed. de 1991, México, UNAM, 2000, p. 71.
} 
2.- Tendo em conta esta restrição do direito à protecção judicial efectiva, teria sido obviamente preferível que a Administração da Justiça tivesse sido suspensa na sua totalidade e que todos os prazos processuais tivessem sido fixados, bem como a expiração do estatuto de limitações na esfera jurídica.

A isto deveria ter sido acrescentado o necessário aumento das dotações orçamentais para a Administração da Justiça, uma vez que a sua reforma, absolutamente necessária, exige não só as acções legislativas adequadas, mas também um aumento significativo das dotações orçamentais.

No entanto, podemos observar que a crise originada pela COVID-19 intensificou o caminho empreendido pelo legislador espanhol sobre justiça, de modo que a falta de meios económicos na Administração da Justiça se tornou secular, a que se juntaram sucessivas reformas cujo princípio orientador é o de encorajar a fuga do processo civil.

Finalmente, podemos falar de reduções processuais autênticas e salientar que com as reduções processuais (lei instrumental) vem a liquidação dos direitos (substantivos). E o mais grave: as reduções processuais fazem proliferar todo o tipo de fraudes, violações e enganos sobre direitos, o que significa regressar, de alguma forma, à lei da selva mercantil - retirar os bens ao cliente para não os pagar.

\section{REFERÊNCIAS}

Alcalá-Zamora y Castillo, N., Proceso, autocomposición y autodefensa. Contribución al estudio de los fines del proceso, reimpresión de la $3^{\underline{a}}$ ed. de 1991, México, UNAM, 2000.

Beceña, F., Notas de Derecho Procesal Civil, 1932, Madrid, (s.d.) Litografía E. Nieto.

Cappelletti, M., La oralidad y las pruebas en el proceso civil, trad. Sentis Melendo, S., Buenos Aires, EJEA, 1972.

Chiovenda, G., Instituciones de Derecho Procesal Civil, Vol. III, trad. Gómez Orbaneja, E., Madrid, Ed. Rev. Derecho Privado, 1954.

Díez-Picazo Giménez, I., «Artículo 24», en Alzaga Villaamil, O., Comentarios a la Constitución Española de 1978, Tomo III, Madrid, Cortes Generales-Editoriales de Derecho Reunidas, 1996.

Fairén Guillén, V., Teoría General del Derecho Procesal, México DF, UNAM, 1992. 
Garberí Llobregat, J., Constitución y Derecho Procesal. Los fundamentos constitucionales del Derecho Procesal, 1. ${ }^{\mathrm{a}}$ ed., Madrid, Civitas-Thomson Reuters, 2009.

Gutiérrez-Alviz y Armario, F.; Moreno Catena, V., «Artículo 120. Actuaciones judiciales», en Alzaga Villaamil, O., Comentarios a la Constitución Española de 1978, Tomo IX, Madrid, Cortes Generales-Editoriales de Derecho Reunidas, 1996, p. 391-411.

Herrera Abián, R., La inmediación como garantía procesal (en el proceso civil y penal), Granada, Comares, 2006.

Majada, Técnica del informe ante juzgados y tribunales. Oratoria forense, 5. a ed., Barcelona, Bosch, 1991

Martín Diz, F., «Oralidad y eficiencia del proceso civil: Ayer, hoy y mañana», en Carpi, F., Ortells, M. (Editores), Oralidad y escritura en un proceso civil eficiente, Vol. II: Comunicaciones, Valencia, Universidad de Valencia, 2008, p. 25-38.

Montero Aroca, J., «La nueva Ley de Enjuiciamiento Civil española y la oralidad», Derecho PUCP, № 53, 2000, p. 583-668.

Picó y Junoy, J., «El principio de Oralidad en el Proceso Civil Español», en Carpi, F., Ortells, M. (Editores), Oralidad y escritura en un proceso civil eficiente, Vol. I: Ponencias generales e informes nacionales, Valencia, Universidad de Valencia, 2008, p. 361-370.

Storme, M., «Más voz y menos letra: En defensa de la oralidad en los procesos judiciales (versión resumida)», en Carpi, F., Ortells, M. (Editores), Oralidad y escritura en un proceso civil eficiente, Vol. I: Ponencias generales e informes nacionales, Valencia, Universidad de Valencia, 2008, p. 47-52.

Taruffo, M., «Oralidad y escritura como factores de eficiencia en el proceso civil (Versión abreviada)», en Carpi, F., Ortells, M. (Editores), Oralidad y escritura en un proceso civil eficiente, Vol. I: Ponencias generales e informes nacionales, Valencia, Universidad de Valencia, 2008, p. 205-219.

Torres Rosell, N., «¿Era necesario y útil el nuevo procedimiento en derecho de familia?», Diario La Ley, № 9656, Sección Plan de Choque de la Justicia / Tribuna, 18 de Junio de 2020, s/p.

Torres Rosell, N., «¿La aceleración de la actividad judicial depende de la restricción de derechos procesales?: modificación y supresión de recursos en el 
proceso penal (propuestas 4.6 y 4.13 del CGPJ)», Diario La Ley, № 9664, Sección Plan de Choque de la Justicia / Tribuna, 1 de Julio de 2020, s/p.

Wach, A., Conferencias sobre la Ordenanza Procesal Alemana, traducción de Krotoschin, E., Buenos Aires, Ediciones Jurídicas Europa-América, 1958. 